\title{
An Investigation into the Effect of Slope Angle of Hub Cap Geometry against the Efficiency of Ship Propeller in the Presence of PBCF
}

\author{
Insanu Abdilla Cendikia Abar ${ }^{1, a, *}$, I Ketut Aria Pria Utama ${ }^{1, b}$ and Muhammad Iqbal 2,c \\ ${ }^{1}$ Department of Naval Architecture, Institut Teknologi Sepuluh Nopember, Surabaya, Indonesia \\ ${ }^{2}$ Department of Naval Architecture, Universitas Diponegoro, Semarang, Indonesia \\ a.Insanu.Abar16@mhs.na.its.ac.id,b.kutama@na.its.ac.id,c.m_iqbal@undip.ac.id \\ *corresponding author
}

Keywords: $\quad$ Propeller Boss Caps Fins, Hub Geometry, Energy Saving Device

\begin{abstract}
The use of Energy-Saving Devices (ESDs) is a way to decrease fuel consumption and greenhouse gas emission on a ship. Not only to reduce fuel consumption, but also the use of ESDs can manage environmental pollution especially air pollution. Propeller boss cap fins $(\mathrm{PBCF})$ is one of ESDs which has a function to help the main propeller gaining more efficiency. However, the configuration of hub slope on a different type of hub cap is very sensitive to whole propeller system performance. The sensitivity of the slope of the hub may affect the different results on the efficiency of PBCF. This is taken into consideration in propeller design with and without the application of PBCF. This analysis was done at full scale using CFD-based RANS method. The result indicated enhancement around 1,3-1,5\% on propeller efficiency after adding PBCF with convergent cap type.
\end{abstract}

\section{Introduction}

Waste of fuel and exhaust pollution is now one of the problems in the field of shipping. As an effort to retrenchment fuel and reduce air pollution due to flue gas, the shipping worlds have begun to develop various Energy Saving Devices (ESDs). The International Maritime Organization (IMO) enacts an Energy Efficiency Design Index (EEDI) which is scheduled in January 2014 to reduce carbon-dioxide on shipping operation and building [1]. The development of ESDs is an effort to improve efficiency in ship operations. Focus on this problem is to create more efficient ships.

There are many ways to decrease fuel consumption such as reducing required power for propulsion, required power for equipment on board, and substituting fuel power (partially) by renewable energies like wind and solar energies [2]. The efficiency of the propeller is one of the key issues affecting engine performance. If the performance of the propeller cannot produce the desired efficiency then fuel consumption from the engine will not fit with the initial design. Development of ESDs on the propeller is aimed to reduce the lost flow around the propeller. The loss of flow around propeller is caused by the slip on the blades, the wake flow inequality leading to rotation of the blades, hub or tip vortex [3]. 
Hub vortex is one of the problems on propeller performance. With the emerging vortex on the propeller hub, it will reduce the speed and decrease the efficiency of the blades. Not only reduces the performance of the blades, but hub vortex also erodes the rudder. The interaction between rudder and propeller creates several problems such as cavitation caused by low velocity of the vessel, periodic impact due to rotation of the blades to ship structure or rudder, undefined natural side force due to hydrodynamic loads [4].

Considering the problems of the hub vortex in 1988 appearred the idea of developing Propeller Boss Cap Fins (PBCF) [5]. PBCF can increase thrust and decrease propeller torque by removing hub vortex due to rotation generated by the fins [6]. In Propeller Open Water Test (POT) experiments, PBCF can improve efficiency directly, while the full-scale trial can reduce power by $3.7 \%$ [1]. PBFC has been installed on 16 vessels and increase the efficiency by $3.5 \%$ [7].

One part of the geometry on PBCF that affects performance is the shape and angle of the slope on the hub. Research has been conducted with different hub types by [1,8]. A study on the use of divergent hubs [1] resulted in decreased efficiency, while [8] found that different hub type affect the resulting vortex. From these two studies, it can be concluded that there is a need for further study on the slope angle of the PBCF and the hub type of PBCF to obtain the appropriate PBCF design.

\section{Energy Savings Devices}

Energy saving devices (ESDs) is a tool that serves as an effort in saving the use of energy consumption. The various concepts of energy saving are evaluation of the wasted power loss [9]. Fuel consumption can be reduced by optimizing the parts on ship construction such as ship hull, ship propellers, and ship steering or by reducing the cost of operation through speed control, and route optimization $[10,11]$. The most crucial thing in the application of propulsion is interaction of resistance, torque, and thrust force. By aligning these three things, we can decrease resistance and increase speed and RPM shafts.

Many ESDs are often applied on ship propulsion and still under development such as Pre-swirl, Duct, and Propeller Boss Cap Fins [12]. Pre-swirl is placed on the propeller flow region and is designed to apply the propeller flow efficiency, as can be seen in Fig.1 The pre-swirl placement is between stern and propeller. From the placement of the Pre-swirl flow can lead well towards the propeller. Pre-swirl focuses wake flow which has an opposite rotating stream with propeller [10]. Pre Swirl can regenerate the drag from the hull of the vessel to positive thrust and provide an efficiency of $4 \%$ [13].

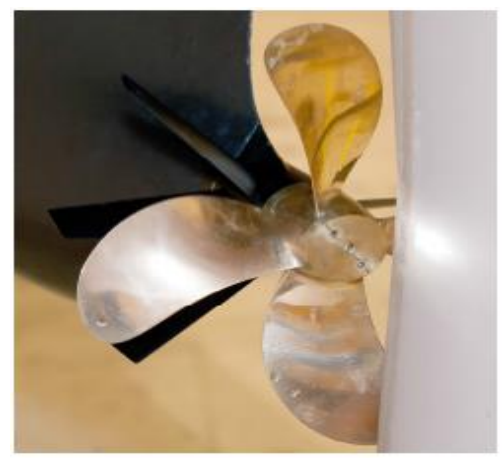

Figure1: Pre-Swirl [13]

The duct can also be called a nozzle mounted around the propeller function focuses the flow from hull to propeller shown in Fig. 2. The duct can reduce the wasted axial flow of the propeller, reduce thrust deduction, and increase uniform flow [9]. The duct can increase thrust propeller by supporting stator to regenerate thrust to positive and increase the efficiency of $6 \%$ [13]. 


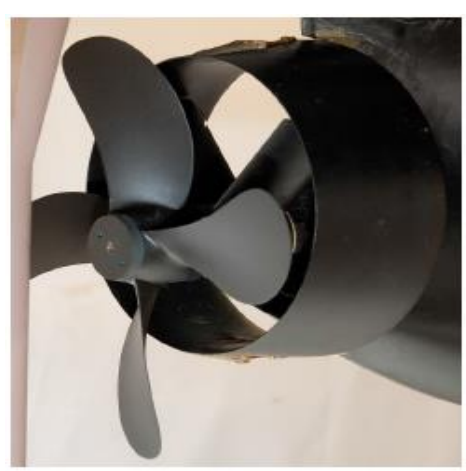

Figure 2: Duct [13]

PBCF is an innovation in ESDs on propulsion by addition of fins on the boss cap propeller, as can be seen in Fig. 3. PBCF function to fix propeller flow by removing hub vortex hence propeller gaining efficiency. PBCF is propulsion ESD which converted normal hub into a hub with fins that number of fins same as the number of propeller blades. [14]. By removing hub vortex, PBCF can reduce fuel consumption cost approximately $3-7 \%$ [2]. By installing $\mathrm{PBCF}$, the occurrence of hub vortex because slipstream can be eliminated and increase efficiency by $2 \%$ [13].

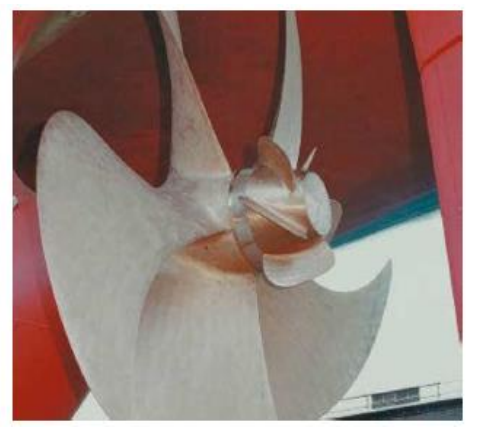

Figure.3 Propeller Boss Cap Fins [13]

\section{Propeller Boss Cap Fins}

Many problems arise in ship propulsion systems can affect propeller performance and result in fuel consumption. Some problems in propulsion are cavitation and vortex. The vortex hub causes thrust decrease by $3 \%$ to $5 \%$, thrust in the hub decrease by $2 \%$ and in the blade decrease by $2 \%$ to $3 \%$ [15]. Some problem like erosion has been found on rudder sister ship and it caused by bubble vortex that occurs due to slipstream [16].

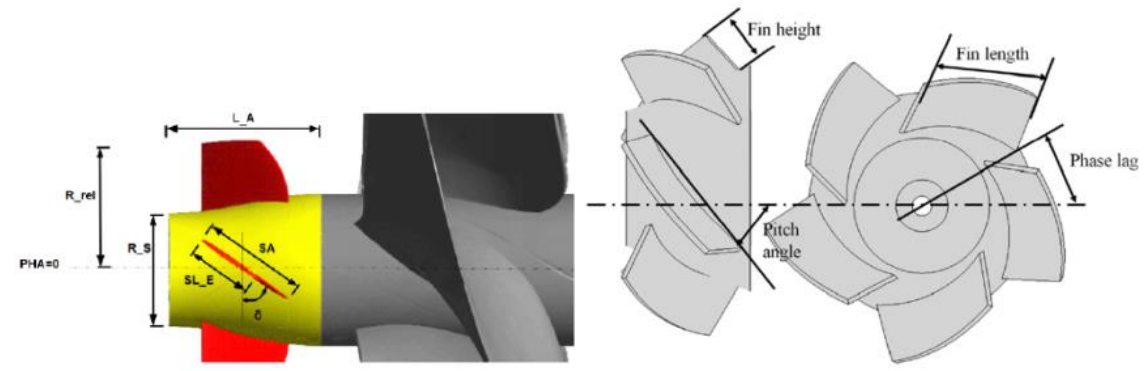

Figure 4: PBCF Variation Parameter [17, 18] 
PBFC offers increased efficiency, particularly in the propeller flow. The efficiency is created by eliminating the vortex hub, increasing thrust, and decreasing the torque [19]. By eliminating the vortex hubs, the erosion of the rudder and the weight of the propeller workload can be overcome by the installation of PBCF.

Due to the problem of propulsion began to develop ESDs to optimize the flow of propeller and propeller performance efficiency. PBCF is one solution of flow problems in the propeller. Since 1988, PBCF development studies have been undertaken to improve the efficiency generated by PBCF. PBCF has several parameters that can be varied like axial position fins on PBCF by [1, 14, 17, 21], pitch angle from fins [1, 14, 17, 21], hub diameter [21], and some researchers have conducted a study on it. In Figure 4 we can see some parts of PBCF that can be varied.

The development list of PBCF parameters that have been studied further by many scientists, as can be seen in Table 1.

All of the research on PBCF development has found out that almost all variations on fins can improve efficiency. However, when the conventional hubs are replaced into PBCF with different hub types and slope angles, the propeller efficiency decreases. This problem caused by PBCF not in suitable with the shape of the hub and it cause vortex on hub propeller.

Each conventional hub type has different vortex characteristics. A simple analysis has been done using the CFD method by [8] from each hub shape against vortex generated. Fig. 5, show effect visualization from each hub which delivers a different vortex.
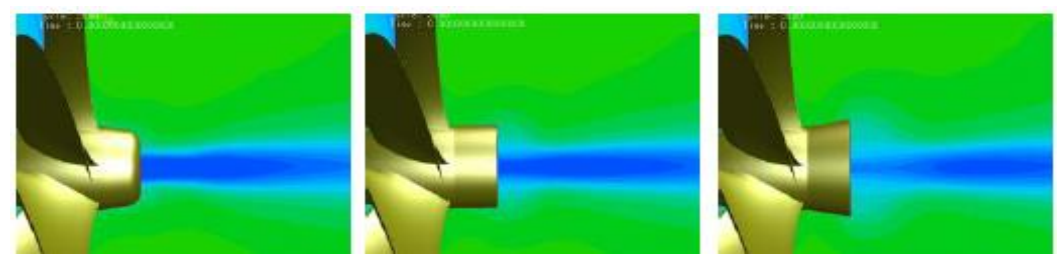

Figure 5: Vortex of each type of hub [8]

Table.1: Research Has Been Done on PBCF

\begin{tabular}{|c|c|c|c|c|c|c|c|c|c|c|c|c|}
\hline \multirow[b]{2}{*}{ Author } & \multicolumn{11}{|c|}{ PBCF Variation Parameter } & \multirow[b]{2}{*}{ Efficiency } \\
\hline & $\begin{array}{l}\text { Reynold } \\
\text { Number }\end{array}$ & $\begin{array}{l}\text { Radius } \\
\text { Fin }\end{array}$ & $\begin{array}{c}\text { Axial } \\
\text { Position }\end{array}$ & Pitch Angle & $\begin{array}{c}\text { Hub } \\
\text { Diameter }\end{array}$ & $\begin{array}{c}\text { Phase } \\
\text { Lag }\end{array}$ & $\begin{array}{l}\text { Fin Chord } \\
\text { Lenght }\end{array}$ & $\begin{array}{c}\text { Shape } \\
\text { Fin }\end{array}$ & \begin{tabular}{|c|} 
Optimization \\
Fin Parameter
\end{tabular} & $\begin{array}{c}\text { Load } \\
\text { Distribution }\end{array}$ & $\begin{array}{c}\text { Shape and } \\
\text { Angle of } \\
\text { Hub }\end{array}$ & \\
\hline Lim, 2014 [1] & & $\mathrm{v}$ & & $\mathrm{v}$ & & $\mathrm{v}$ & $\mathrm{v}$ & $\mathrm{v}$ & & & $\mathrm{v}$ & decrease \\
\hline Katayama, 2015 [8] & & & & & & $\mathrm{v}$ & & & & & & increase \\
\hline Hsin, 2009 [14] & & $\mathrm{v}$ & $\mathrm{v}$ & $\mathrm{v}$ & & & & & & & & increase \\
\hline Seo, 2016 [17] & & $\mathrm{v}$ & & $\mathrm{v}$ & & $\mathrm{v}$ & $\mathrm{v}$ & & & & & increase \\
\hline Druckenbrod, 2015 [18] & & & & & & & & & $\mathrm{v}$ & & & increase \\
\hline Hansen, 2011 [20] & $\mathrm{v}$ & & & & & & & & & & & increase \\
\hline Ghasemmi, 2012 [21] & & $\mathrm{v}$ & $\mathrm{v}$ & & $\mathrm{v}$ & & & & & & & increase \\
\hline Kawamura, 2013 [22] & $\mathrm{v}$ & & & & & & & & & & & increase \\
\hline Mizzi, 2017 [23] & & & & & & & & & $\mathrm{v}$ & & & increase \\
\hline Park, 2016 [24] & & & & $\mathrm{v}$ & & $\mathrm{v}$ & $\mathrm{v}$ & & & & & increase \\
\hline Cheng, 2014 [25] & & & & & & & & & & $\mathrm{v}$ & & increase \\
\hline
\end{tabular}
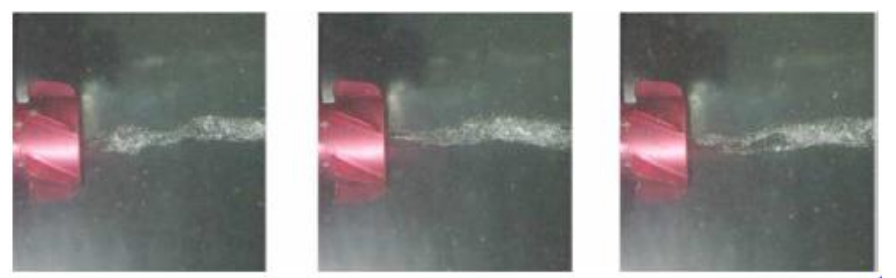

Figure 6: Vortex on PBCF with divergent hub type [1] 
We can see from Fig. 6 attach PBCF on a divergent cap can affect the size of hub vortex. Hub vortex affects the thrust and torque from the main propeller.

In general, this is an interesting development, where the change in hub type used by PBCF and the slope is very risky on the resulting efficiency. This, the importance of these two parameters for further investigation. The need to adjust the shape of fins with fins type so that there is no decrease in the efficiency of the PBCF.

\section{Example of Application}

The experiment data were carried out [26], the main propeller selected for this experiment is present with diameter $=2 \mathrm{~m}$, Pitch $=1.6 \mathrm{~m}$, Ae/Ao $=0.55$, Blade Number $=4, \mathrm{RPM}=257$, Advance Velocity $=9.48 \mathrm{knot}$, turbulence modeling using standard k-epsilon. 3D model for propeller can be seen in Fig.7.

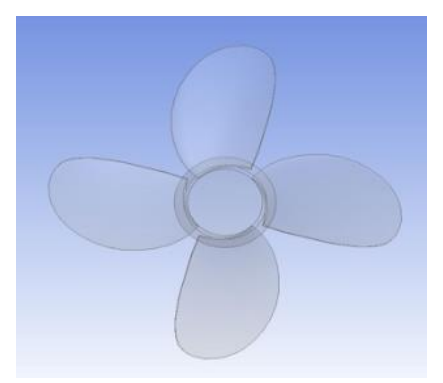

Figure 7: Propeller 3D Model

Computational domain is defined at $3 \mathrm{D}$ for upstream, $5 \mathrm{D}$ for downstream, and 3D for diameter boundary ( $\mathrm{D}$ is propeller diameter ). Computational domain is shown in Fig.8.

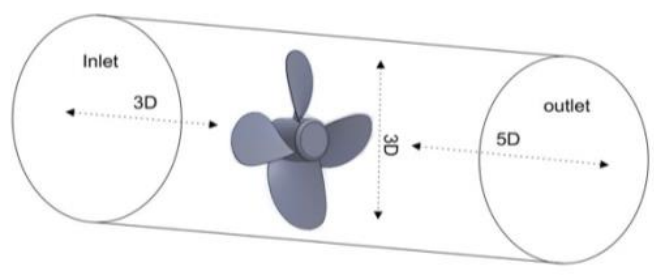

Figure 8: Computational Domain

After obtained 3D model from the main dimension of the propeller. Furthermore, CFD analysis is compared with previous studies [26] whether the configuration used is appropriate. However, the comparison results obtained close to the previous CFD analysis as shown in Table II.

Table 2: CFD Result Comparison

\begin{tabular}{|l|c|c|l|}
\hline & KT & KQ & $\begin{array}{c}\text { Efficiency } \\
(\eta)\end{array}$ \\
\hline CFD & 0,153 & 0,215 & 0,643 \\
\hline Previous Experiment & 0,142 & 0,201 & 0,623 \\
\hline
\end{tabular}

The next step after finding the right CFD configuration is continued with the variation on PBCF to be used on the main propeller. The variation in slope angle of hub propeller referred to this experiment described in Fig. 8. Aspects to be analyzed in the experiment include the effect of changing the angle of the propeller hub cap geometry against the efficiency of the propeller, the use 
of PBCF with a divergent and convergent cap which has varied the slope angle and varying the fin number used in the divergent cap. For slope angle explained on Fig.9 and kinds of cap used on PBCF is shown in Fig. 10.

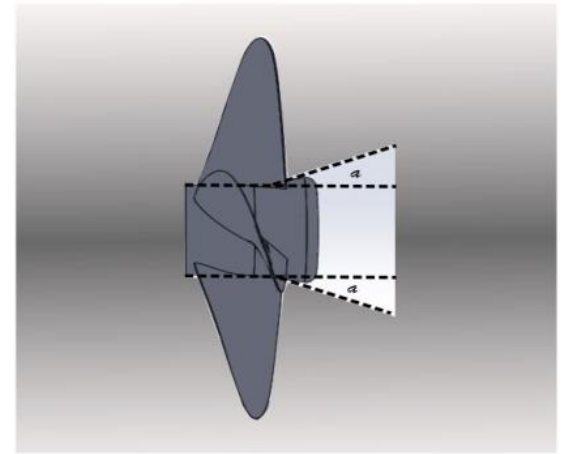

Figure 9: Slope angle of hub propeller

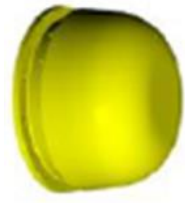

(a)

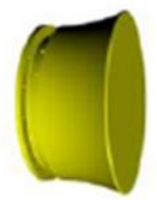

(b)

Figure10: Kinds of Cap (a) Convergent Cap (b) Divergent Cap [8]

After analyzing using CFD software, we get two different case results is shown in Table III. Regarding the value of Thrust Coefficient $\left(\mathrm{K}_{\mathrm{T}}\right)$ on the whole propeller system. First, the result from two kinds of cap between convergent and divergent. Second, the result between two kinds of cap with addition fins.

Table 3: KtT Propeller

\begin{tabular}{|c|c|c|c|c|}
\hline Propeller Type & $\mathbf{0}^{\mathbf{0}}$ & $\mathbf{5}^{\mathbf{0}}$ & $\mathbf{1 0}^{\mathbf{0}}$ & $\mathbf{1 5}^{\mathbf{0}}$ \\
\hline \multicolumn{5}{|c|}{ Without PBCF } \\
\hline Divergent Cap & 0,153 & 0,149 & 0,146 & 0,141 \\
\hline Convergent Cap & 0,153 & 0,154 & 0,155 & 0,155 \\
\hline \multicolumn{5}{|c|}{ With PBCF } \\
\hline Convergent 4 fins & 0,155 & 0,156 & 0,160 & 0,161 \\
\hline Divergent 4 fins & 0,155 & 0,144 & 0,135 & 0,127 \\
\hline Divergent 6 fins & 0,156 & 0,132 & 0,127 & 0,125 \\
\hline
\end{tabular}

For the first case without addition PBCF, we get contrast result. we can see in Fig.11 convergent cap get increasement $\mathrm{K}_{\mathrm{T}}$ while divergent cap gets decreasement on $\mathrm{K}_{\mathrm{T}}$. 


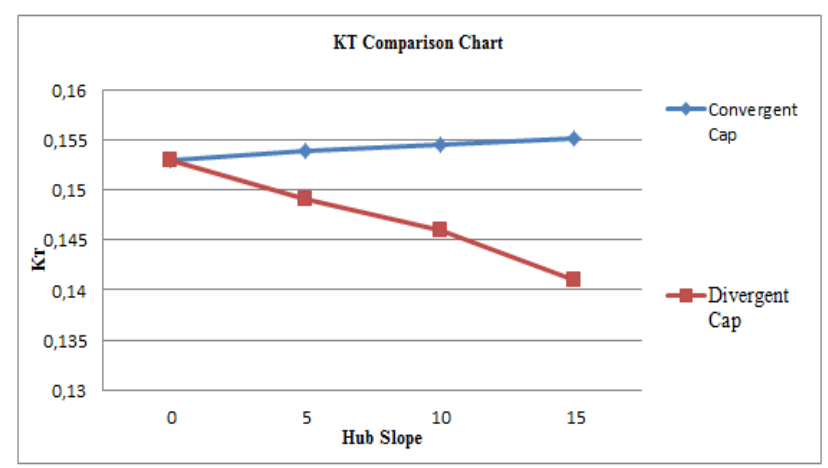

Figure 11: KT Comparison Chart without Addition PBCF

For first result case without addition PBCF, we get contrast result. we can see in Fig.11 convergent cap get increasement $\mathrm{K}_{\mathrm{T}}$ while divergent cap gets decreasement on $\mathrm{K}_{\mathrm{T}}$.

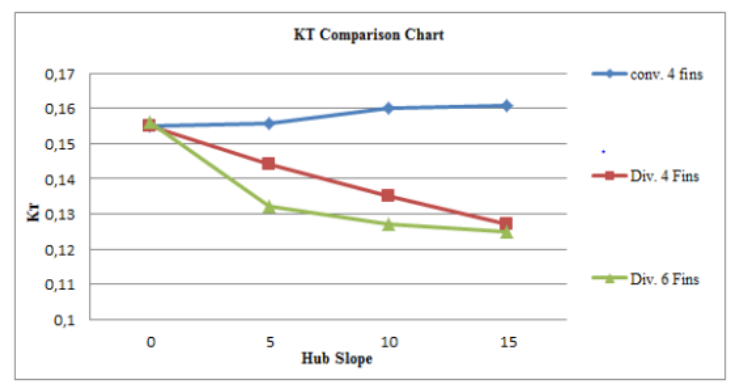

Figure 12: KT Comparison Chart with Addition PBCF

For the second case with addition PBCF, we get the same result. we can see on Fig.12 divergent cap with an addition 4 fins get decreasement on $\mathrm{K}_{\mathrm{T}}$, even with an addition more fins it makes worst on decresement value of $\mathrm{K}_{\mathrm{T}}$. This happens because the increment of the slope angle and addition more fins on the hub resist the thrust generated from the main propeller. After adding PBCF to the propeller system, thrust should be increased, therefore propeller can gain efficiency $[5,19]$.

Table 4: $\mathrm{K}_{\mathrm{q}}$ Propeller

\begin{tabular}{|l|l|l|l|l|}
\hline Propeller Type & $\mathbf{0}^{\mathbf{0}}$ & $\mathbf{5}^{\mathbf{0}}$ & $\mathbf{1 0}^{\mathbf{0}}$ & $\mathbf{1 5}^{\mathbf{0}}$ \\
\hline Without PBCF & 0,0215 & 0,0214 & 0,0212 & 0,0210 \\
\hline Divergent Cap & 0,0215 & 0,0213 & 0,0210 & 0,0207 \\
\hline Convergent Cap & 0,0215 & 0,0215 & 0,0214 & 0,0212 \\
\hline With PBCF & 0,0215 & 0,0219 & 0,0219 & 0,0220 \\
\hline Convergent 4 fins & 0,0209 & 0,0219 & 0,0220 & 0,0223 \\
\hline Divergent 4 fins
\end{tabular}


The estimation of torque coefficient $\left(\mathrm{K}_{\mathrm{Q}}\right)$ is shown in Table IV present different result between the case with and without addition PBCF. Before adding PBCF into the propeller system there is a decrease in the value of $\mathrm{K}_{\mathrm{Q}}$ as shown in Fig.13.

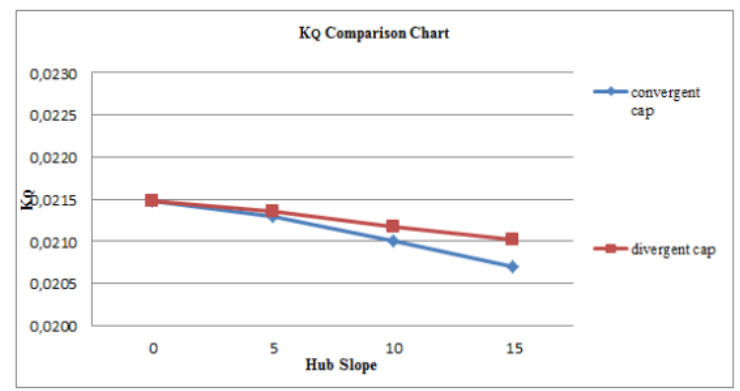

Figure 13: KQ Comparison Chart without Addition PBCF

After adding fins and increasement of slope angle hub cap especially on divergent cap value of $\mathrm{K}_{\mathrm{Q}}$ constantly increase as shown in Fig.14. The increase in $\mathrm{K}_{\mathrm{Q}}$ influenced by the increase in the number of fins and slope angle on divergent cap type. PBCF should decrease torque according to [5, 19] therefore propeller can gain efficiency.

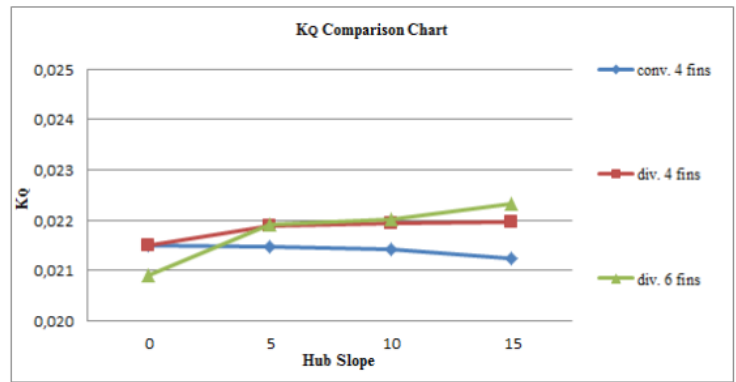

Figure14: KQ Comparison Chart with Addition PBCF

From CFD analysis we obtain the contour flow velocity on the convergent 4 fins with angle of boss cap of 15 degrees as shown in Fig. 15.

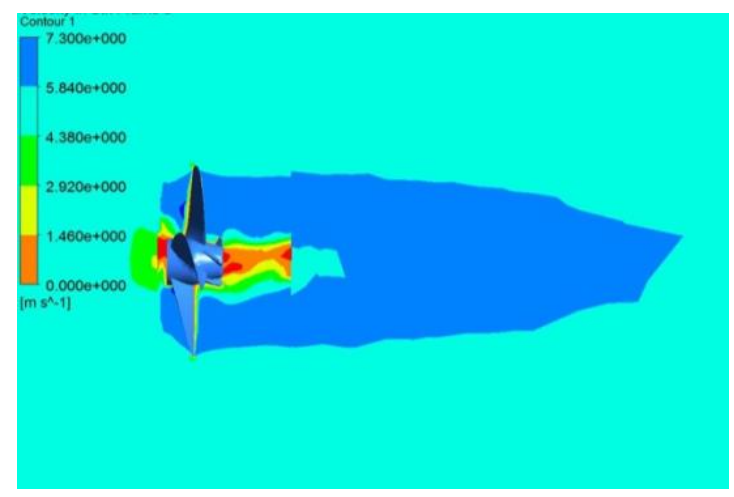

Figure15: Contour Velocity Convergent 4 Fins 15 Degree

The flow color behind convergent cap on zero velocity means there is no stream behind the cap and thrust color more dominant. Therefore, propeller system can produce more thrust. 
Table 5: Propeller Efficiency

\begin{tabular}{|c|c|c|c|c|}
\hline Propeller Type & $\mathbf{0}^{\mathbf{0}}$ & $\mathbf{5}^{\mathbf{0}}$ & $\mathbf{1 0}^{\mathbf{0}}$ & $\mathbf{1 5}^{\mathbf{0}}$ \\
\hline \multicolumn{5}{|c|}{ Without PBCF } \\
\hline Divergent Cap & 0,643 & 0,634 & 0,623 & 0,609 \\
\hline Convergent Cap & 0,643 & 0,655 & 0,668 & 0,678 \\
\hline \multicolumn{5}{|c|}{ With PBCF } \\
\hline Convergent 4 fins & 0,653 & 0,658 & 0,677 & 0,687 \\
\hline Divergent 4 fins & 0,653 & 0,598 & 0,557 & 0,524 \\
\hline Divergent 6 fins & 0,676 & 0,544 & 0,522 & 0,507 \\
\hline
\end{tabular}

After the calculation of efficiency, we found that convergent cap in a case before and after adding PBCF can increase efficiency propeller. By adding PBCF on convergent cap efficiency increase around 1,3 - 1,5\%. Different result found on divergent cap case, decreasement on efficiency propeller found in a case before and after adding PBCF as shown in Table 5. As presented in [27] comparison of the performances for the cap relative to standard cone shape type

\section{Conclusions}

A review studies on the development of PBCF have been conducted based on the work done by many scientists around the world. PBFC is one of the ESDs which is useful in improving the efficiency of ship propulsion. A lot of follow-up research has been done to obtain the best efficiency from PBCF. From several studies, variation of fins can improve efficiency. While the variation in the shape of the hub and the angle of the slope can lead to decreased efficiency. This becomes important in the adjustment of fins when variations are made on the slope and shape of the hub in order to obtain increased efficiency. The effective need for further research on the variation of the hub shape and the angle of the hub.

From a simple CFD analysis it was found that the change in the shape of the hub and the angle of the hub can affect the thrust, torque, and propeller efficiency. Hence, the need to adjust the form of PBCF with the type or angle of the slope of the hub form. Finally, CFD analysis provides the following result :

- Hub cap selection on design propeller influence thrust, torque, and efficiency of the propeller system.

- Increase slope angle on a different type of hub cap can produce a different result on thrust, torque, and efficiency propeller system.

- Addition PBCF on propeller system does not always give good impact.

- The configuration of divergent cap used in PBCF does not produce an increase in efficiency but decreases efficiency while convergent cap can produce an increase in efficiency.

\section{References}

[1] S.S. Lim, T.W. Kim, D.M. Lee, C.G. Kang, and S.Y. Kim, "Parametric Study of Propeller Boss Cap Fins for Container Ships”. Int. J. Nav. Archit. Ocean Eng,2014,6:187 205.

[2] K. Hochkirch, and V. Bertram, "Engineering Options for More Fuel Efficient Ships", Conference Green Technology v.1, 2010, Canada. 
[3] F. Mewis. "A Novel Power-Saving Device for Full-Form Vessels”, First International Symposium on Marine Propulsion, 2009, Norway.

[4] M. Felli, M. Falchi "Propeller tip and hub vortex dynamics in the interaction with a rudder", Springer-Verlag Exp Fluids, 2011,51:1385-1402.

[5] K. Ouchi, M. Ogura, Y. Kono, H.Orito, T. Shiotsu, M. Tamashima, H. Koizuka, "A Research and Development of PBCF (Propeller Boss Cap Fins) - Improvement of Flow from Propeller Boss”, Journal of the Society of Naval Architects of Japan, 163, 1988, pp.66-78.

[6] M. Cheng, and C. Hao- Peng, "The design of propeller and propeller boss cap fins (PBCF) by an integrative method”, Journal of Hydrodinamic, 2014,26(4):586-593, China.

[7] T. Nojiri, N. Ishii, H. Kai, “Energy Saving Technology of PBCF (Propeller Boss Cap Fins) and Its Evolution”, Journal of the JIME Vol. 46, No.3, 2011, pp. 350-358.

[8] K. Katayama, Y. Okada, and A. Okazaki, "Optimization of the Propeller with ECO-cap by CFD”. Fourth International Symposium on Marine Propulsors, 2015, USA.

[9] T. Terwisga, "On the working principles of Energy Saving Devices”, Third International Symposium on Marine Propulsors, 2013, Australia.

[10] Y. Sharifi, H. Ghassemi, H. Zanganeh, "Various Innovative Technologic Devices in Shipping Energy Saving and Diminish Fuel Consumption”, International Journal of Physics, 2017, Vol. 5, No. 1, 21-29.

[11] A.F Molland, S.R Turnock, D.A Hudson, and I.K.A.P Utama, “Reducing Ship Emission: A Review of Potensial Practical Improvements in the Propulsive Efficiency of Future Ships”, Internasional Journal of Maritime, Vol 156 pp 175 - 188, 2014, English.

[12] M. Khorasanchi, S. Day, O. Turan, A. Incecik, S. Turkmen, "What to expect from the hydrodynamic energy saving Devices”, Low Carbon Shipping Conference'13, 2013, London.

[13] J. Dang, H. Chen, and G. Dong, “An Exploratory Study on the Working Principle of Energy Saving Devices (ESD)”, Symposium on Green Ship Technology Greenship, 2011, China.

[14] C.Y. Hsin, B.H. Lin, C.C Lin, The Optimum Design of a Propeller Energy-Saving Device by Computational Fluid Dynamics, Computational Fluid Dynamics 2008 pp 655-660, Springer, Berlin, Heidelberg.

[15] F. Ochi, T. Fujisawa, T. Ohmori, and T. Kawamura, "Simulation of propeller hub vortex flow", First International Symposium on Marine Propulsors, 2009, Norway.

[16] T. Terwisga, P. Fitzsimmons, L. Ziru, E. J. Foeth, “Cavitation Erosion - A review of physical mechanisms and erosion risk models", Proceedings of the 7th International Symposium on Cavitation - Paper No. 41, 2009, USA.

[17] J. Seo, S. J. Lee, B. Han, and S. H. Rhee, "Influence Design Parameter Variation for Propeller-Boss-Cap-Fins on Hub Vortex Reduction”, Journal of Ship Research, Vol. 60 No. 4 pp. 203-218, 2016.

[18] M. Druckenbrod, K. Wang, L. Greitsch, H.-J. Heinke, M. Abdel-Maksoud, "Development of Hub Cap Fitted With PBCF”. Fourth International Symposium on Marine Propulsors, 2015, USA.

[19] K. Ouchi, M. Tamashima "Research and Development on PBCF (Propeller Boss Cap Fins)”, Technical Paper for PBCF presented at PRADS' 89, October, 1989, BULGARIA.

[20] H. R. Hansen, T. Dinham-Peren, and T. Nojiri, “Model and Full Scale Evaluation of a 'Propeller Boss Cap Fins' Device Fitted to An Aframax Tanker”, Second International Symposium on Marine Propulsors, 2011, Germany.

[21] H. Ghassemi, A. Mardan, and A. Ardeshir, "Numerical Analysis of Hub Effect On Hydrodinamic Performance of Propellers with Inclusion of PBCF to Equalize the Induced Velocity”, Journal of Polish Maritime Research 2 (73) Vol 19, 2012, pp $17-24$.

[22] T. Kawamura, K. Ouchi, S. Takeuchi, "Model and Full Scale CFD Analysis of Propeller Boss Cap Fins $(P B C F)$ ", Third International Symposium on Marine Propulsors, 2013, Australia.

[23] K. Mizzi, Y. K. Demirel, C. Banks, O. Turan, P. Kaklis, and M. Atlar, "Design Optimisation of Propeller Boss Cap Fins for Enhanced Propeller Performance.", Applied Ocean Research 62, 2017, pp. 210-222.

[24] S. Park, B. Han and B. Chang, “A Study On The Propulsive Performance Of HI-FIN”, 12th International Conference on Hydrodynamics, 2016, Netherlands.

[25] J.P. Chen, J. Su, J.W. Jie, and L. Yang, "Investigation On Propulsion And Flow Field Of Ships With Energy Saving Devices Using CFD Prediction And Model Tests”, The 12th International Conference on Hydrodynamics, 2016, Netherlands.

[26] S. Prakash, D.R. Nath, “A Computational Method for Determination of Open Water Performance of a Marine Propeller”, International Journal of Computer Applications, 2012, Volume 58-No.12. 
[27] M. Alter, "Final Report and Recommendations to the 22 ${ }^{\text {nd }}$ ITTC", The Specialist Committee on Unconventional Propulsors, 1999. 